\title{
ENDIVIDAMENTO EM FIRMAS COM ALTA PROPENSÃO À EXPROPRIAÇÃO: O CASO DE FIRMAS COM UM CONTROLADOR
}

DEBT IN FIRMS WITH A HIGH PROPENSION TO EXPROPRIATION: THE CASE OF CONTROLLED FIRMS

\section{RESUMO}

O mercado brasileiro caracteriza-se por estruturas de propriedade concentradas, em um ambiente legal propício à expropriação de minoritários, o que pode influenciar os incentivos aos decisores e, potencialmente, afetar a decisão sobre a utilização de dívida como forma de financiamento das empresas. Este trabalho buscou estudar o nível de endividamento em empresas controladas por um único acionista, aqui classificadas como empresas com alta propensão à expropriação de minoritários, em uma amostra de 322 empresas negociadas na Bovespa entre 1996 e 2002. Os resultados apontaram um menor nível de endividamento dessas empresas, de forma consistente com a hipótese de maior poder de monitoração dos credores. Por outro lado, o seu nível de endividamento aumenta quando decresce o direito dos majoritários aos fluxos de caixa gerados, o que sinaliza para a utilização da dívida como mecanismo de governança.

\section{Rodrigo Oliveira Soares}

Professor do Centro de Ciências Econômicas, Universidade do Vale do Rio dos Sinos

rodsoares@terra.com.br

\section{Gilberto de Oliveira Kloeckner}

Professor da Escola de Administração, Universidade Federal do Rio Grande do Sul gokloeckner@ea.ufrgs.br

Recebido em 27.03.2008. Aprovado em 11.08.2008

Avaliado pelo sistema double blind review

Editor Científico: Organizadores do Fórum

\begin{abstract}
The Brazilian capital market is characterized by concentrated ownership structures, in a legal environment which is propitious to the expropriation of minority shareholders, what may influence the incentives to decision makers, and mainly, affect the decision on debt as a financing source. We aimed to study the leverage of firms controlled by a single shareholder, which we classify as high propension to minority expropriation firms. The sample consisted of 322 company traded at Bovespa between 1996 and 2002. Tests results showed that the firms controlled by a single shareholder used a smaller amount of debt, what is consistent with the high monitoring capacity of debtholders. Conversely, the level of debt increases as the cash flow rights of the controller shareholder decreases, what may be a signal of the use of debt as a governance device.
\end{abstract}

PALAVRAS-CHAVE Estrutura de capital, estrutura de propriedade, problema de agência, expropriação, mercado brasileiro. KEYWORDS Capital structure, ownership structure, agency problems, expropriation, Brazilian market. 


\section{INTRODUÇÃO}

O artigo seminal de Modigliani e Miller (1958) estabeleceu as premissas sob as quais a decisão sobre a estrutura de capital das empresas é irrelevante. A partir de então, têm sido construídas teorias que visam explicar o endividamento das empresas a partir do relaxamento desses pressupostos, o que tem permitido enfoques distintos por diferentes correntes teóricas.

Este trabalho busca embasamento na teoria de agência (JENSEN e MECKLING, 1976; JENSEN, 1986), que tradicionalmente considera conflitos entre gerentes e acionistas e entre acionistas e credores. Entretanto, o primeiro conflito tende a ocorrer em firmas onde se dá a separação de propriedade e controle pela pulverização do capital. Aspectos do mercado brasileiro como a estrutura de propriedade concentrada e ampla utilização de ações sem direito a voto (LEAL, CARVALHAL-DA-SILVA e VALADARES, 2002; ALDRIGHI e MAZZER NETO, 2007; VALADARES, 2002), além de um ambiente legal com baixo nível de proteção aos minoritários (LA PORTA e outros, 1999A; BRITO e LIMA, 2005), permitem especulações sobre a importância, no país, do conflito entre majoritários e minoritários. Tais características afetam, potencialmente, os incentivos para a ação dos indivíduos na empresa, podendo influir na decisão sobre o nível de endividamento, fenômeno evidenciado por Procianoy e Schonorrenberger (2004) ao estudarem a influência da estrutura de propriedade na estrutura de capital das empresas no Brasil.

Este estudo visa a investigar a decisão de endividamento em situações onde há alta propensão à expropriação de minoritários. Argumenta-se que a existência de um único controlador pessoa física, aliada ao descasamento entre direitos a fluxos de caixa e direito ao voto, em um ambiente legal onde há fraca proteção aos acionistas minoritários, funciona como um incentivo à expropriação. Por sua vez, a estrutura de incentivos em empresas com alta propensão à expropriação pode influenciar a decisão de endividamento, uma vez que a dívida pode atuar como um mecanismo de governança.

Ressalta-se, como contribuição, a consideração da oportunidade específica proporcionada pelo mercado brasileiro, incluindo tanto o ambiente legal quanto a concentração acionária, que geram incentivos à expropriação de minoritários. Utilizaram-se, como definição de empresa com alta propensão à expropriação, as empresas com um único acionista controlador, sendo que a definição de controle foi considerada a partir de três diferentes critérios, conforme será visto posteriormente.

Como estrutura de trabalho, propõe-se, primeiramente, considerar aspectos sobre o conflito entre majoritários e minoritários, contextualizando o problema no Brasil. Em seguida, explicitam-se as proposições de pesquisa e o seu método. Na seção seguinte, analisam-se os resultados. Finalmente, apresentam-se as considerações finais.

\section{CONCENTRACCÃO ACIONÁRIA E 0 CONFLITO ENTRE MAJORITÁRIOS E MINORITÁRIOS}

Uma questão deve ser considerada ao analisar esse conflito: por que possuir grande quantidade de ações de uma só empresa se a diversificação diminui o risco? Uma resposta possível é que deve haver benefícios que justifiquem esse maior risco. O conflito entre majoritários e minoritários toma forma pela expropriação desses últimos e, de acordo com Dick e Zingales (2004), essa expropriação, também referida como extração de benefícios privados do controle, vem ocupando lugar central na literatura.

A pulverização do capital, conforme destacado por La Porta e outros (1999), não é a forma de estrutura de propriedade dominante no mundo. Apesar disso, grande parte das teorias no campo de finanças a considera implícita ou explicitamente. No ambiente brasileiro, a estrutura de propriedade possui um importante papel. Valadares e Leal (2000) investigaram a concentração acionária nas empresas S.A. de capital aberto no Brasil em 1997. Os resultados mostraram uma estrutura concentrada para a maior parte das empresas, o que praticamente elimina a possibilidade de takeovers no Brasil. Isso pode contribuir para a ineficiência, pois a possibilidade de tomada de controle incentiva os gestores a maximizar o valor das ações. Outro ponto destacado no estudo foi a ampla utilização de ações com direitos de voto diferenciados (apenas 35\% das empresas estudadas não possuíam preferenciais). A existência no Brasil de estruturas piramidais e ações com direitos diferenciados de voto proporcionam o controle com um percentual de capital menor que 50\%, o que potencializa ainda mais os incentivos causados pela existência de controle acionário, tornando a estrutura de propriedade um importante aspecto a ser considerado no mercado brasileiro.

Por sua vez, o ambiente legal é um assunto que tem ocupado lugar de destaque nos estudos sobre finanças corporativas. Uma vez que as normas e a obrigatoriedade do seu efetivo cumprimento são elementos essenciais para fazer valer os direitos dos investidores - acionistas quanto credores -, o ambiente legal passa a ser de vital importância. La Porta e outros (1998) estudaram a proteção legal aos direitos dos acionistas em diversos países, 
encontrando diferenças na qualidade da proteção aos investidores, de acordo com o tipo de base legal vigente. $\mathrm{O}$ estudo apontou que nos países baseados na Lei Comum Britânica os direitos dos investidores têm sido mais protegidos, sendo que os países baseados na Lei Civil Francesa, caso do Brasil, são os que proporcionam o menor nível de proteção aos investidores. Trabalhos sobre o ambiente legal e a expropriação de minoritários têm sido empreendidos no Brasil. Exemplos são os de Nenova (2001) e Saito (2001). O ambiente com fraca garantia legal também é explorado no trabalho de Brito e Lima (2005), que estudaram a estrutura de capital das empresas no Brasil, inclusive a análise da origem dos controladores (privados ou públicos, nacionais ou estrangeiros). Os autores encontraram evidências que permitiram concluir que as empresas privadas nacionais são mais expostas aos custos de agência, fortalecendo o pecking order.

$\mathrm{O}$ ambiente legal brasileiro, somado à estrutura de propriedade concentrada, proporciona oportunidades para expropriação, originando o conflito de agência entre controladores e minoritários.

\section{Um único controlador versus acordo de acionistas}

O controle acionário, além existir quando um acionista possui mais que $50 \%$ dos votos, também pode ser exercido por grupos, por meio dos chamados acordos de acionistas. Aldrighi e Mazzer Neto (2007) definem tais acordos como "um registro legal de compromisso de voto acordado entre alguns acionistas".

O controle exercido por meio de acordo de acionistas, com mais de um grande participante no grupo controlador, tende a tornar as empresas menos propensas à expropriação, já que os interesses do grupo de controle podem, dependendo da ocasião, ser diversos. Pode haver diferenças de perfis no grupo de controle, em termos de aversão ao risco (diferentes níveis de diversificação), em termos de necessidades de caixa e horizonte de investimentos (miopia de investimentos), entre outras. Ademais, o incentivo à monitoração por parte de grandes acionistas (problema de free rider - ver Grossman e Hart, 1980) é maior, fazendo com que haja tendência de monitoração cruzada entre os participantes do controle.

Por sua vez, o controle exercido por apenas um acionista pessoa física tende a exacerbar o incentivo à expropriação, devido ao seu maior poder discricionário.

\section{Incentivos para a minimização do conflito}

Uma primeira análise pode considerar que os controladores consumirão o máximo de benefícios privados, o que pode ser questionado com base em Jensen e Meckling (1976), que afirmam que o mercado é composto, inclusive, pelos minoritários e, sendo racional, irá prever esse problema. Isso pode causar rejeição do mercado às ações da firma, diminuindo seu valor e dificultando, ou desincentivando, a captação a partir dessa modalidade de financiamento.

Por sua vez, a dívida pode ser utilizada como um mecanismo de governança, de forma a minimizar a expropriação. Jensen e Meckling (1976) apregoam que firmas endividadas possuem menos fluxos livres de caixa a serem consumidos, além da maior capacidade de monitoração dos credores. Analisando, por sua vez, o percentual sobre os fluxos de caixa a que o controlador tem direito, os incentivos à expropriação são tanto menores quanto maior for a sua participação no capital total. Assim à medida que aumentam os direitos a fluxos de caixa, diminui a função da dívida como elemento atenuador desse conflito.

Dadas as condições de existência do conflito entre majoritários e minoritários no Brasil, proporcionadas pela legislação e pela concentração da propriedade, além das evidências empíricas verificadas, pode-se esperar que o país seja adequado para estudos empíricos sobre estrutura de capital em ambientes propícios à extração de benefícios privados do controle.

\section{Proposições derivadas}

Considerando-se que a definição de controle incentiva a extração de benefícios privados por parte do majoritário e, ainda, que os credores possuem, além da maior capacidade de monitoração que os acionistas minoritários, a prerrogativa de requerer a falência da empresa em casos de inadimplência, uma primeira proposição pode ser efetuada:

Proposição 1: Empresas onde existe um acionista controlador definido recorrem menos à dívida para financiar o seu crescimento.

Entretanto, o argumento de Valadares (2002), sobre a importância de mecanismos inibidores do conflito de agência, vai de encontro à Proposição 1 . Considerando o endividamento como um desses mecanismos, empresas com controle definido tenderiam a se endividar, sinalizando ao mercado a atenuação dos conflitos. Além disso, diante de um provável baixo interesse do mercado, por emissões de firmas com alto potencial de expropriação, a dívida pode ser a única alternativa para o financiamento externo. Isso justifica uma negação da Proposição 1 :

Proposição 2: Empresas onde existe um acionista controlador definido recorrem mais à dívida para financiar o seu crescimento. 
A terceira proposição parte de dois motivos: o primeiro é que, quanto maior o percentual de capital do controlador, maior será a possibilidade de que a perda dos benefícios privados do controle, decorrentes da maior monitoração causada pelo endividamento, seja compensada pelos fluxos de caixa oriundos de novos projetos. Isso é consistente com a idéia de alinhamento de interesses de Jensen e Meckling (1976). O segundo é que o controle exercido por estruturas indiretas aumenta os incentivos para o financiamento por ações, pois o percentual a ser subscrito pelo controlador, de forma a manter controle, é menor.

Proposição 3: Em empresas onde existe um acionista controlador definido, quanto maior o percentual de ações que o controlador detém, maior será o endividamento da empresa.

Por outro lado, o desejo de manter a possibilidade de novas emissões e a rejeição do mercado por ações de empresas controladas, em que o controlador possui um baixo percentual de fluxos de caixa, são argumentos contra a Proposição 3. Quanto maior a posse de capital do controlador, menor o incentivo à expropriação, pois o aumento da sua participação diminui o seu benefício com a expropriação, além de o consumo de benefícios privados contribuir para baixar o preço das ações, e, quanto maior sua propriedade, maior a perda. Assim, empresas controladas em que o controlador possui grande parte dos fluxos de caixa não precisariam sinalizar por meio da dívida, suscitando uma quarta proposição que contradiz a terceira.

Proposição 4: Em empresas onde existe um acionista controlador definido, quanto maior o percentual de ações que o controlador detém, menor será o endividamento da empresa.

\section{MÉTODO}

Este trabalho utilizou dois testes não-paramétricos, além de regressões com dados em painel, para os testes relacionados às proposições. Nesta seção, são descritos os procedimentos de amostragem e coleta de dados, bem como os testes efetuados.

\section{A amostra e a coleta dos dados}

$O$ universo corresponde às empresas negociadas na Bovespa, no período de 1996 a 2002. Foram excluídas as instituições financeiras, pois o endividamento faz parte da sua atividade fim. A amostra final foi composta por 322 empresas. Cabe ressaltar que se exigiu que as empresas apresentassem informações para pelo menos três anos no período estudado.

As fontes dos dados são distintas: os contábeis, bem como aqueles para o critério de definição de controle CON3, foram extraídos do Economática Pró ${ }^{\circledR}$ (Economática, 2003). Já os dados sobre estrutura de propriedade, para os critérios CON1 e CON2, vêm das IAN's (CVM, 2003). Finalmente, os dados sobre fundos de pensão foram retirados de uma lista de associados à Associação Brasileira das Entidades Fechadas de Previdência Complementar (ABRAPP, 2003).

\section{Testes não-paramétricos}

O objetivo desses testes foi proporcionar maior robustez ao tratamento estatístico, pois eles são menos restritivos quanto aos pressupostos acerca das distribuições estatísticas. Tais testes (testes I e II) foram efetuados com o auxílio do software SPSS ${ }^{\circledR}$.

Teste I

O teste I consistiu na separação dos dados em duas categorias, de acordo com a definição de controle, sendo realizado o teste U de Mann-Whitney entre essas e os indicadores de endividamento. Assim, foi verificada a existência de diferenças no nível de endividamento das categorias. $\mathrm{O}$ sinal da relação foi verificado pela média dos ranks.

Foram considerados três critérios para definição de controle:

Definição 1: empresa com controle definido é aquela em que existe um acionista, pessoa física, que possui, direta e/ou indiretamente (por meio de pirâmides), $50 \%$ das ações com direito a voto, desconsiderando as ações em tesouraria, ou seja, dividindo os percentuais do primeiro nível por: 1 menos o percentual de ações em tesouraria (doravante referida como CON1).

Definição 2: empresa com controle definido é aquela em que existe um acionista, pessoa física, que possui, direta e/ou indiretamente, $50 \%$ das ações com direito a voto, desconsiderando, além das ações em tesouraria, os acionistas dispersos (componentes do grupo com a denominação "outros", ou seja, aqueles com menos do que $5 \%$ do capital) (doravante denominada CON2).

Definição 3: empresa com controle definido é aquela em que existe um acionista, pessoa física ou jurídica, que possui, diretamente, $50 \%$ das ações com direito a voto. Nesse caso desconsideram-se possíveis pirâmides abaixo do primeiro nível (referida como CON3). 
Foram utilizados quatro indicadores de endividamento, descritos a seguir (entre parênteses e em negrito, as siglas para a referência aos indicadores): Exigível a Longo Prazo / Patrimônio Líquido (ELP_PL); (Passivo Circulante + Exigível a Longo Prazo) / Patrimônio Líquido (PCELP_ PL); (Passivo Circulante + Exigível a Longo Prazo) / Ativo Total (PE_AT); e Exigível Total/(Exigível Total + Valor de Mercado da Empresa) (DIV_VR).

\section{Teste II}

O teste II utilizou a prova não-paramétrica da Análise de Variância por ranks de Kruskal-Wallis nas proposições 3 e 4. Para o teste, uma subamostra de empresas com controle definido (de acordo com cada um dos critérios CON1, CON2 e CON3) foi dividida em quintis, de acordo com o percentual acionário do controlador, de forma semelhante à usada por Grinstein e Michaely (2005). Possíveis diferenças entre os quintis denotariam que são oriundos de populações diferentes.

\section{Análise de dados em painéis}

Os testes III e IV utilizaram regressões com dados em painéis não balanceados. A análise de dados em painéis possui a vantagem de permitir a análise de questões que não podem ser verificadas somente por meio de dados transversais ou de dados em séries temporais (HSIAO, 1998). Proporciona, ainda, maior número de observações, aumentando os graus de liberdade e reduzindo a colinearidade entre as variáveis explicativas, o que aumenta a eficiência das estimações. Foi utilizado o teste de Hausman, que verifica a correlação entre o erro e os regressores, para decidir entre painéis com efeitos fixos ou aleatórios.

\section{Teste III}

O modelo para o teste das proposições 1 e 2 , está especificado na equação, onde Endit é o endividamento da empresa $i$ no ano $t$; ExContit é uma dummy para a existência de controle acionário na empresa $i$ no ano $t$; e $V C_{j i t}$ são variáveis de controle no modelo (variável $j$, de um total de 8 , medida para a empresa $i$ no ano $t$ - tais variáveis são descritas no Quadro 1:

$$
\text { End }_{i t}=\alpha+\beta \text { ExCont }_{i t}+\sum_{j=1}^{8} \delta_{j} V C_{j i t}+\varepsilon_{i, t}
$$

\section{Teste IV}

O modelo usado nas proposições 3 e 4 possui duas diferenças para o do Teste III: a amostra, composta por firmas com controle acionário definido, e a substituição da variável ExCont, por FCCont, que discrimina os direitos a fluxos de caixa do controlador. A equação descreve o Teste IV e o Quadro 1 apresenta as variáveis usadas nos testes III e IV:

$$
\text { End }_{i t}=\alpha+\beta \text { FCCont }_{i t}+\sum_{j=1}^{8} \delta_{j} V C_{j i t}+\varepsilon_{i, t}
$$

Quanto às variáveis independentes para o controle de fatores exógenos ao modelo, elas referem-se às dimensões suscitadas em diversos modelos que buscam os determinantes da estrutura de capital das empresas, cujos efeitos esperados sobre o endividamento são resumidos em Terra (2002a; 2002b), e podem ser visualizados no Quadro 2 [Brito e Lima (2005) apresentam uma tabela para sumarizar as relações teóricas entre quatro fatores e as teorias de trade-off e pecking-order, totalmente consistente com o Quadro 2].

Adicionalmente às dimensões sugeridas por Terra (2002), foram inseridas no modelo variáveis dummy para o controle dos diferentes regimes cambiais vividos no Brasil no período de estudo, para a existência de fundos de pensão entre os acionistas da empresa e para a existência de capital público na base acionária.

As variáveis de controle, sua definição operacional, bem como as relações esperadas, são apresentadas a seguir:

Oportunidades de crescimento: um indicador de oportunidades de crescimento que vem sendo utilizado em diversos estudos é o valor de mercado dividido pelo valor patrimonial (FAMA e FRENCH, 2002). Além desse, também foi utilizada a proxy crescimento anual das vendas. A relação prevista pelo pecking order entre oportunidades de crescimento e alavancagem é positiva, pois as empresas, de acordo com a hierarquia preferencial das fontes de financiamento, preferem a dívida à emissão de ações. Entretanto o problema do subinvestimento, suscitado por Myers (1977), considera que as empresas com altas oportunidades de crescimento serão menos endividadas. A teoria dos custos de falência também prevê um menor endividamento para empresas com altas oportunidades de crescimento. Essa variável foi ressaltada por Terra (2002a; 2002b) como uma das que são capazes de distinguir entre as teorias explicativas da estrutura de capital.

Lucratividade: a lucratividade é uma dimensão importante para a verificação das predições do pecking order, pois o modelo prediz que a primeira fonte de financiamento a ser escolhida pela gerência são os lucros retidos 
(MYERS, 1984; MYERS e MAJLUF, 1984). A medida utilizada como indicador de lucratividade foi a razão entre o lucro antes do pagamento de juros, impostos, depreciação e amortização (EBITDA) e o ativo total, doravante denominado EBITDA_AT.

Tamanho: o tamanho é uma das variáveis ressaltadas por Terra (2002a; 2002b) como capazes de diferenciar o pecking order das demais vertentes teóricas sobre a estrutura de capital. O modelo de Myers e Majluf (1984) e Myers (1984) prevê um relacionamento negativo entre essa variável e o endividamento das empresas. Empresas de maior porte tendem a produzir mais caixa, o que facilita o seu financiamento por meio de lucros retidos, que são a primeira opção na hierarquia do pecking order. No entanto, o tamanho pode indicar uma menor

Quadro 1 - Resumo das variáveis do modelo de teste em painéis
SÍMBOLO
VARIÁVEL
PROXIES
RELAÇÃO ESPERADA
RAZÃO TEÓRICA

Variável dependente para o teste das proposições do modelo proposto

\begin{tabular}{|l|l|r} 
& & ELP/PL \\
& $(\mathrm{PC}+\mathrm{ELP}) / \mathrm{PL}$ \\
End $_{i, t}$ & Endividamento & $(\mathrm{PC}+\mathrm{ELP}) / \mathrm{AT}$ \\
& $\mathrm{ET} /(\mathrm{ET}+\mathrm{VM})$
\end{tabular}

VARIÁVEIS INDEPENDENTES PARA O TESTE DAS PROPOSIÇÕES DO MODELO PROPOSTO

\begin{tabular}{|c|c|c|c|c|}
\hline \multirow[b]{2}{*}{ ExCont $_{i, t}$} & \multirow[b]{2}{*}{ Existe ou não de controle acionário } & $\operatorname{EXCON1}\left({ }^{*}\right)$ & Negativa & Proposição 1 \\
\hline & & $\begin{array}{l}\operatorname{EXCON2}(*) \\
\operatorname{EXCON} 3\left({ }^{*}\right)\end{array}$ & Positiva & Proposição 2 \\
\hline \multirow[b]{2}{*}{ FCCont $_{i, t}$} & \multirow[b]{2}{*}{ Fluxos de caixa do controlador } & FCCON1 $(* *)$ & Positiva & Proposição 3 \\
\hline & & $\begin{array}{l}\operatorname{FCCUN} 2\left({ }^{* *}\right) \\
\operatorname{FCCON} 3(* *)\end{array}$ & Negativa & Proposição 4 \\
\hline
\end{tabular}

VARIÁVEIS INDEPENDENTES PARA O CONTROLE DE FATORES EXÓGENOS AO MODELO PROPOSTO

\begin{tabular}{|l|l|c|c|c|}
\hline Luc $_{i, t}$ & Lucratividade & EBITDA/AT & Indeterminada & Variável de controle \\
\hline Tam $_{i, t}$ & Tamanho & LNAT & Indeterminada & Variável de controle \\
\hline OC $_{i, t}$ & Oportunidades de crescimento & $\begin{array}{l}\text { VM/VP } \\
\text { CRESVEN }\end{array}$ & Indeterminada & Variável de controle \\
\hline Vol $_{i, t}$ & Risco do negócio & DPLO/AT & Negativa & Variável de controle \\
\hline Tang $_{i, t}$ & Tangibilidade dos ativos & IMOB/AT & Positiva & Variável de controle \\
\hline Camb $_{i, t}$ & Câmbio fixo & Dummy & Indeterminada & Variável de controle \\
\hline FP $_{i, t}$ & Acionista fundo de pensão & Dummy & Positiva & Variável de controle \\
\hline Pub & Capital público & Dummy & Positiva & Variável de controle \\
\hline \hline
\end{tabular}

LEGENDA DE SIGLAS:

ELP = Exigível a longo prazo; $P C$ = Passivo circulante; $P L$ = Patrimônio líquido; $A T$ = Ativo total; VM = Valor de mercado da ação; VP $=$ Valor patrimonial da ação; CRESVEN = Crescimento anual das vendas; LNAT = Logaritmo natural do ativo total; EBITDA = Lucro antes de juros, imposto, depreciação e amortização; DPLO = Desvio padrão do lucro operacional (últimos 5 anos); IMOB = Ativo imobilizado líquido

$\left({ }^{*}\right)$ Dummy para controle acionário, de acordo com as definições CON1, CON2 e CON3.

$\left({ }^{* *}\right)$ Direito do controlador aos fluxos de caixa, pelas definições CON1, CON2 e CON3. 
probabilidade de falência (Titman e Wessels, 1988) e, portanto, a vertente do trade-off apregoa uma relação positiva entre tamanho e endividamento. Também se pode argumentar que empresas maiores tendem a ser mais conhecidas e gozar de alguma reputação, conforme Diamond (1989), o que pode facilitar o acesso à dívida. Como indicador para essa variável, foi utilizado o logaritmo natural do ativo total (LNAT).

Risco do negócio: empresas com maior volatilidade dos fluxos de caixa tenderão a ser menos endividadas, controlando as oportunidades de crescimento, devido à necessidade de flexibilidade para cobrir déficits de caixa (FAMA e FRENCH, 2002). Como proxies para volatilidade, utilizou-se o desvio padrão do lucro operacional dividido pelo ativo total. Optou-se por tal indicador, em relação à volatilidade da receita, devido ao fato de o lucro operacional incluir os efeitos da alavancagem operacional sobre o resultado. Os desvios padrão foram computados, levando-se em consideração o período dos últimos cinco anos.

Tangibilidade dos ativos: ativos tangíveis podem ser utilizados como garantia real para dívidas, diminuindo o risco de empréstimos. Dessa forma, pode-se esperar que empresas cujos ativos são em sua maior parte intangiveis tenham maior dificuldade de se endividar, e, conseqüentemente, espera-se uma relação direta entre a tangibilidade dos ativos e o nível de endividamento. Como proxy para a tangibilidade dos ativos foi utilizada a razão entre o ativo imobilizado líquido e o ativo total.

Câmbio fixo: uma vez que houve uma mudança no regime cambial a partir de 1999, foi utilizada uma dummy para captar seus possíveis efeitos no endividamento das empresas. A relação entre esta variável e o nível de endividamento é indeterminada.

Fundos de pensão: uma vez que o investimento no mercado acionário é obrigatório para os fundos de pensão, pode-se argumentar sobre a maior capacidade de monitoração dessas organizações. Assim, empresas que possuem fundos de pensão como acionistas, podem ter menor potencial para o conflito de agência entre majoritários e minoritários. Tal variável visa a um controle adicional sobre a identidade dos acionistas da empresa.

Capital público: a presença de capital público na base acionária das empresas também foi controlada devido à possibilidade de que empresas onde existe capital dessa natureza possuam menor possibilidade de falência.

O Quadro 3 resume as proposições teóricas efetuadas neste trabalho, bem como os testes a serem utilizados para testá-las.

A estatística descritiva para as variáveis utilizadas nos testes descritos pode ser visualizada na Tabela 1 .

\section{RESULTADOS DOS TESTES}

Partindo da apresentação dos dados utilizados neste trabalho, bem como da forma como foram coletados, passa-se, então, à apresentação e à discussão dos resultados com base no que se mostrou na seção anterior.

\section{O teste U de Mann Whitney}

Os resumos dos testes U constam na Tabela 2. Destacase que, dependendo do critério para controle acionário, diferentes proxies do nível de endividamento foram sig-

Quadro 2 - Dimensões testadas e o sinal esperado de acordo com a classificação teórica

\begin{tabular}{|l|c|c|c|}
\hline & \multicolumn{2}{|c|}{ EIMENSÕES } & \multicolumn{2}{c|}{ EFEITO ESPERADO SOBRE O ENDIVIDAMENTO } \\
\hline & STATIC TRADE-OFF & ASSIMETRIA INFORMACIONAL & PECKING ORDER \\
\hline Tangibilidade & Positivo & Positivo & Positivo \\
\hline Lucratividade & Positivo & Positivo & Negativo \\
\hline Tamanho & Positivo & Negativo & Negativo \\
\hline Oportunidades de crescimento & Negativo & Negativo & Positivo \\
\hline Impostos & Positivo & Indeterminado & Indeterminado \\
\hline Risco do negócio & Negativo & Negativo & Negativo \\
\hline
\end{tabular}

Fonte: Terra (2002a; 2002b). 
nificativas. PE_AT somente foi significativa para o critério de controle CON3. Por outro lado, as variáveis DIV_VR, ELP_PL e PCELP_PL apresentaram significância ao nível de 5\% (ou menos) para o critério de controle CON2. No caso do critério CON1, as variáveis proxy ELP_PL e DIV_VR apresentaram resultado significativo a 5\%. Também o sinal da relação apresentou diferenças: para os critérios CON1 e CON2, em cinco dos modelos a relação entre endividamento e existência de controle apresentou-se negativa. Somente uma relação positiva significativa foi apontada, para o critério de controle CON3.

O fato de o nível de endividamento ter se mostrado significativamente diferente no grupo com controle definido, em relação ao grupo sem definição de controle, em seis das doze observações, sugere a relevância do controle para a estrutura de capital das empresas.

\section{Teste one-way Anova de Kruskal-Wallis}

O teste de Kruskal-Wallis utilizou a subamostra de empresas com controle definido. A Tabela 3 traz, para cada proxy para controle acionário definido, a significância do teste e o sinal da relação entre o percentual de capital do controlador e o nível de endividamento da empresa. Essa última relação foi verificada por meio da ordenação do rank médio dos quintis, e, quando não houve relação linear com a dívida, o sinal da relação foi considerado ambíguo.

Para a definição de controle CON1, verifica-se que o indicador baseado no valor de mercado da empresa (DIV_VR) foi significativo a $1 \%$, sendo a proxy PE_AT significativa a 5\% e ELP_PL a 10\%. Para o critério CON2 a relação foi significativa a 1\% para os indicadores ELP_PL, PE_AT e DIV_VR. O último critério (CON3) apresentou relação significativa a $1 \%$ para as sub-rogadas PE_AT e DIV_VR e a 5\% para a proxy PCELP_PL. Sobre os sinais das relações, nota-se que para todas as variáveis ele foi considerado ambíguo, ou seja, não houve uma relação linear, direta ou inversa entre os ranks médios dos quintis de percentual acionário do controlador e os indicadores de endividamento.

O direito a fluxos de caixa do controlador mostrou relevância em sua relação com o endividamento em nove dos doze testes, sugerindo, apesar da ambigüidade dos sinais, a importância dos potenciais conflitos entre majoritários e minoritários para o estudo da estrutura de capital no Brasil.

\section{Tratamento para o descarte de outliers}

A inclusão de valores extremos em análises paramétricas pode distorcer resultados, o que fez com que se optasse pelo descarte dos outliers antes dos testes paramétricos. Por um lado, isso pode ser criticado, pois a pesquisa visa a explicar a realidade, total ou parcialmente. Por outro, argumenta-se que esse procedimento possui a vantagem de melhoria na qualidade dos testes paramétricos, sendo válido dizer que os dados representam melhor o comportamento médio das variáveis. Para tanto, utilizou-se o critério dos gráficos box-plot, que, segundo Hair e outros (1998), consiste em descartar os dados que não permanecerem no intervalo compreendido entre o valor do primeiro quartil menos $1,5 \mathrm{vez}$ o intervalo interquartílico e o valor do terceiro quartil mais $1,5 \mathrm{vez}$ o intervalo interquartílico.

\section{Quadro 3 - Resumo das proposições efetuadas}

\begin{tabular}{|c|c|c|c|}
\hline \multirow{2}{*}{ PROPOSIÇÃO 1} & \multirow{2}{*}{$\begin{array}{l}\text { Empresas com controle definido } \\
\text { possuem menor endividamento }\end{array}$} & \multirow{2}{*}{$\begin{array}{l}\text { Maior monitoração de credores e pagamento de juros } \\
\text { diminui o consumo de benefícios privados }\end{array}$} & U de Mann-Whitney \\
\hline & & & Dados em painel \\
\hline \multirow{2}{*}{ PROPOSIÇÃO 2} & \multirow{2}{*}{$\begin{array}{l}\text { Empresas com controle definido } \\
\text { possuem maior endividamento }\end{array}$} & \multirow{2}{*}{$\begin{array}{l}\text { Minimização de custos de agência, viabilizando novas } \\
\text { emissões; rejeição do mercado a novas emissões obri- } \\
\text { gando ao endividamento para financiar o crescimento }\end{array}$} & U de Mann-Whitney \\
\hline & & & Dados em painel \\
\hline \multirow{2}{*}{ PROPOSIÇÃO 3} & \multirow{2}{*}{$\begin{array}{l}\text { Relação positiva entre direito a } \\
\text { fluxos de caixa do controlador e } \\
\text { endividamento }\end{array}$} & \multirow{2}{*}{$\begin{array}{l}\text { Quanto menor a propriedade do controlador, maior o } \\
\text { ganho com benefícios privados, e maior a perda destes } \\
\text { benefícios advinda da monitoração de credores e pa- } \\
\text { gamento de juros }\end{array}$} & Kruskal-Wallis \\
\hline & & & Dados em painel \\
\hline \multirow{2}{*}{ PROPOSIÇÃO 4} & \multirow{2}{*}{$\begin{array}{l}\text { Relação negativa entre direito a } \\
\text { fluxos de caixa do controlador e } \\
\text { endividamento }\end{array}$} & \multirow{2}{*}{$\begin{array}{l}\text { Minimização de custos de agência, viabilizando novas } \\
\text { emissões; rejeição do mercado a novas emissões obri- } \\
\text { gando ao endividamento para financiar o crescimento }\end{array}$} & Kruskal-Wallis \\
\hline & & & s em $p$ \\
\hline
\end{tabular}


De todos os indicadores, apenas em dois houve o descarte de mais do que 15\% dos dados: PCELP_PL com $16,56 \%$ e ELP_PL com $16,51 \%$ dos dados. Em outros dois casos (EBITDA_AT com 11,81\% e VOLATLO com $11,57 \%$ ) o percentual descartado situou-se entre $10 \%$ e
$15 \%$. Para as demais variáveis, mais de $90 \%$ dos dados permaneceram. Ademais, os indicadores de fluxos de caixa dos controladores permaneceram com 100\% dos dados.

As estatísticas descritivas após o tratamento para descartar os outliers é apresentada na Tabela 4. Pode-se notar

Tabela 1 - Estatística descritiva

\begin{tabular}{|l|r|r|r|r|r|r|}
\hline ESTATíSTICAS & ELP_PL & PCELP_PL & PE_AT & DIVT_VRMC & CON1 & CON2 \\
\hline Média & 1,6267 & 4,8824 & 0,8275 & 0,5438 & 0,5036 & 0,4799 \\
\hline Desvio padrão & 11,9852 & 78,8425 & 2,8644 & 0,3002 & 0,2311 & 0,2351 \\
\hline Coef. variação & 7,3678 & 16,1483 & 3,4614 & 0,5521 & 0,4589 & 0,4898 \\
\hline $1^{\circ}$ Quartil & 0,0347 & 0,2282 & 0,2613 & 0,3131 & 0,3001 & 0,2792 \\
\hline Mediana & 0,2454 & 0,6427 & 0,4588 & 0,5631 & 0,4955 & 0,4656 \\
\hline $3^{\circ}$ Quartil & 0,7034 & 1,5249 & 0,7024 & 0,8004 & 0,6854 & 0,6699 \\
\hline & & & & & & \\
\hline ESTATísTICAS & EBITDA_AT & LNAT & P_VPA & CRESREC & V0LATLO & IMOB_AT \\
\hline Média & 0,9868 & 12,8264 & 1,1692 & 0,3974 & 0,4639 & 3,8193 \\
\hline Desvio padrão & 10,8827 & 1,7687 & 6,9669 & 8,7515 & 3,9992 & 37,3462 \\
\hline Coef. variação & 11,0281 & 0,1379 & 5,9588 & 22,0232 & 8,6202 & 9,7784 \\
\hline $1^{\circ}$ Quartil & $-0,0016$ & 11,6092 & 0,3000 & $-0,1328$ & 0,0139 & 0,0631 \\
\hline Mediana & 0,0668 & 12,7791 & 0,6000 & $-0,0124$ & 0,0450 & 0,3607 \\
\hline $3^{\circ}$ Quartil & 0,1842 & 13,9928 & 1,0000 & 0,1320 & 0,1053 & 0,8528 \\
\hline
\end{tabular}

Tabela 2 - Resumo do teste U de Mann-Whitney

\begin{tabular}{|c|c|c|c|c|c|}
\hline \multirow{2}{*}{$\begin{array}{c}\text { DEFINIÇÃO DE } \\
\text { CONTROLE }\end{array}$} & ESTATÍSTICA & \multicolumn{4}{|c|}{ VARIÁVEL } \\
\cline { 2 - 6 } & Mann-Whitney U & ELP_PL & PCELP_PL & PE_AT & DIV_VR \\
\hline \multirow{2}{*}{ CON1 } & Z & $-2,4200 * *$ & $-1,5180$ & $-0,0690$ & $-2,2140 * *$ \\
\hline & Sinal da relação & Negativo & Negativo & Negativo & Negativo \\
\hline & Mann-Whitney U & 408739,5 & 416517 & 441143 & 205577 \\
\hline \multirow{2}{*}{ CON2 } & Z & $-2,8980 * * *$ & $-2,2390 * *$ & $-0,3380$ & $-1,9750 * *$ \\
\hline & Sinal da relação & Negativo & Negativo & Negativo & Negativo \\
\hline & Mann-Whitney U & 401182 & 395391 & 379378 & 203325 \\
\hline & Z Z & $-0,0850$ & $-0,5960$ & $-2,1950 * *$ & $-0,3140$ \\
\hline
\end{tabular}

* Sig. a $10 \% \quad * *$ Sig. a $5 \% \quad * * *$ Sig. a $1 \%$ 
uma diminuição substancial na variância das variáveis com o descarte dos valores extremos.

\section{Regressões com dados em painel}

Partindo dos resultados do teste de Hausman, foram efetuadas regressões em painel, para as três definições de controle (CON1, CON2 e CON3), em cada teste (Testes III e IV). Foram testadas a existência de controle (EXCONT), nas proposições 1, 2 e 5, e os fluxos de caixa do controlador onde há controle definido (FCCONT), nas proposições 3, 4 e 6 . Utilizaram-se duas proxies para oportunidades de crescimento (P_VPA e CRESREC), totalizando assim 48 regressões iniciais (24 na amostra total e 24 na subamostra controlada). Os testes para a verificação dos problemas nas regressões são citados no Quadro 4. As estatísticas de Durbin-Watson (DW) detectaram problemas de autocorrelação em diversas das equações.

\section{Tabela 3 - Resumo do teste de Kruskal-Wallis}

\begin{tabular}{|c|c|c|c|c|c|}
\hline \multirow{2}{*}{$\begin{array}{c}\text { DEFINIÇÃO DE } \\
\text { CONTROLE }\end{array}$} & \multirow{2}{*}{ ESTATISTIICA } & \multicolumn{4}{|c|}{ VARIÁVEL } \\
\hline & & ELP_PL & PCELP_PL & PE_AT & DIV_VR \\
\hline \multirow{2}{*}{ CON1 } & Qui quadrado & $8,1197^{*}$ & 5,129 & $9.5176^{* *}$ & $29.4495 * * *$ \\
\hline & Sinal da relação & Ambíguo & Ambíguo & Ambíguo & Ambíguo \\
\hline \multirow{2}{*}{ CON2 } & Qui quadrado & $16.5049 * * *$ & 9,2401 & $17.4313 * * *$ & $42.0922 * * *$ \\
\hline & Sinal da relação & Ambíguo & Ambíguo & Ambíguo & Ambíguo \\
\hline \multirow{2}{*}{ CON3 } & Qui quadrado & 7,7364 & $13.2088^{* *}$ & $28.0869 * * *$ & $24.8093 * * *$ \\
\hline & Sinal da relação & Ambíguo & Ambíguo & Ambíguo & Ambíguo \\
\hline
\end{tabular}

* Sig. a $10 \% \quad * *$ Sig. a $5 \% \quad * * *$ Sig. a $1 \%$

Tabela 4 - Estatística descritiva após o tratamento para o descarte de outliers

\begin{tabular}{|l|c|c|c|c|c|c|}
\hline ESTATÍSTICAS & ELP_PL & PCELP_PL & PE_AT & DIVI_VRMC & FCCON1 & FCCON2 \\
\hline Média & 0,3160 & 0,7570 & 0,4615 & 0,5438 & 0,5036 & 0,4799 \\
\hline Desvio padrão & 0,3928 & 0,8647 & 0,2836 & 0,3002 & 0,2311 & 0,2351 \\
\hline Coef. variação & 1,2429 & 1,1423 & 0,6146 & 0,5521 & 0,4589 & 0,4898 \\
\hline $1^{\circ}$ Quartil & 0,0373 & 0,2412 & 0,2479 & 0,3131 & 0,3001 & 0,2792 \\
\hline Mediana & 0,2062 & 0,5837 & 0,4323 & 0,5631 & 0,4955 & 0,4656 \\
\hline $3^{\circ}$ Quartil & 0,5017 & 1,1801 & 0,6406 & 0,8004 & 0,6854 & 0,6699 \\
\hline & & & & & & \\
\hline ESTATísTICAS & EBITDA_AT & LNAT & P_VPA & CRESREC & VoLATLO & IM0B_AT \\
\hline Média & 0,0738 & 12,8160 & 0,5921 & $(0,0075)$ & 0,0524 & 0,4286 \\
\hline Desvio padrão & 0,1155 & 1,6934 & 0,4770 & 0,1940 & 0,0526 & 0,4505 \\
\hline Coef. variação & 1,5664 & 0,1321 & 0,8056 & $(25,8724)$ & 1,0022 & 1,0512 \\
\hline $1^{\circ}$ Quartil & $(0,0029)$ & 11,6124 & 0,3000 & $(0,1218)$ & 0,0113 & 0,0451 \\
\hline Mediana & 0,0502 & 12,7731 & 0,5000 & $(0,0139)$ & 0,0367 & 0,2989 \\
\hline $3^{\circ}$ Quartil & 0,1442 & 13,9729 & 0,8000 & 0,1103 & 0,0776 & 0,6717 \\
\hline
\end{tabular}


O método de estimação por mínimos quadrados generalizados foi utilizado na tentativa de corrigir a autocorrelação. Para tanto, incluiu-se o termo AR(1), correspondente aos resíduos defasados onde o teste DW detectou o problema. Em dois dos modelos este procedimento foi capaz de eliminar a autocorrelação.

\section{Descrição dos resultados para o Teste III}

As regressões em que não houve problemas de autocorrelação são apresentadas na Tabela 5. Nota-se que a variável EXCONT foi significativa a $1 \%$ na regressão três, que utilizou a variável DIV_VR como indicador de estrutura de capital, sendo apontada uma relação inversa entre a existência de controle e o endividamento.

É importante ressaltar que dois dos modelos constantes na Tabela 5, as regressões 2 e 4 , referem-se à estimação por mínimos quadrados generalizados, com o termo AR(1) utilizado para tratar a autocorrelação, antes detectada no teste de Durbin-Watson. Além de a estatística de DW confirmar a eliminação da autocorrelação, o termo AR(1) mostrou-se significativo a $1 \%$ nas regressões, demonstrando a relevância para a explicação. É importante, entretanto, desconsiderar o $\mathrm{R}^{2}$, pois este leva em consideração a explicação dada pelos resíduos AR(1).

\section{Descrição dos resultados para o Teste IV}

Deve-se atentar para o fato de que a primeira e a terceira regressões da Tabela 6 são idênticas. A primeira utilizou CON1, e a quarta, CON2. O fato de serem idênticas devese, primeiro, aos percentuais de fluxos de caixa do controlador, iguais para CON1 e CON2 (o ajuste para "outros acionistas" foi feito apenas na definição da existência de controle). O que diferencia os percentuais de fluxos de caixa do controlador, utilizando CON1 ou CON2, é que estes somente apresentam valores no caso de existir controle, e CON2 apresenta mais empresas com controle definido do que CON1. Então, o que provavelmente aconteceu foi uma coincidência causada pelos dados faltantes das demais variáveis. Assim, apesar de o teste IV apontar seis modelos sem autocorrelação, são considerados, na análise, apenas cinco.

Dos cinco modelos considerados, o percentual de fluxo de caixa do controlador foi significante em três, correspondentes às regressões 2,5 e 6 , apresentando relação inversa com as variáveis de endividamento, DIV_VR e ELP_PL.

\section{CONSIDERAÇÕES FINAIS}

Os resultados deste trabalho são resumidos no Quadro 5. O teste U de Mann-Whitney confirmou, em 50\% das relações, a diferença entre empresas com e sem um acionista controlador definido, quanto ao nível de endividamento, sendo tal relação positiva, o que aponta a uma confirmação da Proposição 1. Da mesma forma, uma das regressões múltiplas em painel apontou evidências da relação negativa entre controle acionário e o nível de endividamento.

O teste one-way anova de Kruskal-Wallis apresentou significância estatística em nove das doze relações testadas, corroborando a existência de relação entre os direitos a fluxos de caixa do controlador e o nível de endividamento.

Quanto aos testes referentes às Proposições 3 e 4, em todos os modelos de regressão onde a variável FCCONT se mostrou significativa, o sinal da relação com o nível de endividamento foi negativo, sendo suscitadas duas possíveis explicações: (1) empresas com maior potencial para expropriação (as controladas em que o controlador possui baixo direito a fluxos de caixa) têm dificuldades para emitir ações devido a uma possível rejeição do mercado causada por reputação negativa quanto à expropriação, o que pode obrigar ao financiamento do crescimento pelo endividamento; ou (2) tais empresas se endividam como forma de sinalizar ao mercado um menor nível de expropriação, mantendo abertas as possibilidades de emissões futuras, aspecto ressaltado por Valadares (2002).

\section{Quadro 4 - Testes efetuados nos modelos de regressão em painel}

\begin{tabular}{|l|l|l|}
\multicolumn{1}{|c|}{ PROBLEMA } & \multicolumn{1}{|c|}{ PROCEDIMENTO } & \multicolumn{1}{c|}{ RESULTADO } \\
\hline Estacionariedade das séries & Teste de raiz unitária de Dickey-Fuller aumentado & Sem problemas \\
\hline Multicolinearidade & Matriz de correlações (exigido $\rho<0,7)$ & Sem problemas \\
\hline Heterocedasticidade & Estimação robusta por White (correção dos erros padrão) & \\
\hline Autocorrelação & $\begin{array}{l}\text { Teste de Durbin-Watson, e tratamento pela estimação por } \\
\text { mínimos quadrados generalizados. }\end{array}$ & $\begin{array}{l}\text { Autocorrelação em alguns modelos, } \\
\text { descartados da análise neste trabalho. }\end{array}$ \\
\hline
\end{tabular}


Quanto às variáveis de controle utilizadas nos testes, cabe destacar aquelas citadas por Terra (2002a; 2002b), como capazes de diferenciar entre os modelos concorrentes para a explicação da estrutura de capital. As evidências encontradas nos testes não foram claras.
Se, por um lado, a relação negativa entre lucratividade e endividamento corrobora a pecking order, por outro, o tamanho, positivamente relacionado ao endividamento, é incompatível com o modelo de Myers (1984), já que empresas maiores tendem a gerar mais caixa, que

Tabela 5 - Regressões para o teste III onde 0 teste DW não detectou autocorrelação

\begin{tabular}{|c|c|c|c|c|c|c|}
\hline \multicolumn{3}{|c|}{ VARIÁVEIS DEPENDENTES } & ELP_PL & PCELP_AT & DIV_VR & PCELP_AT \\
\hline \multicolumn{3}{|c|}{ Efeitos fixos (EF) ou aleatórios (EA) } & (EF) & (EF) & (EF) & (EF) \\
\hline \multicolumn{3}{|c|}{ Critério para controle acionário } & \multicolumn{2}{|c|}{ CON 2} & \multicolumn{2}{|c|}{ CON3 } \\
\hline \multicolumn{3}{|c|}{ Referência da equação } & (1) & (2) & (3) & (4) \\
\hline \multirow{11}{*}{ 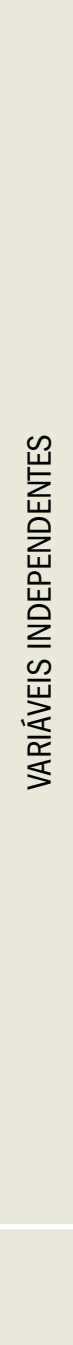 } & $\begin{array}{l}\text { Existência de } \\
\text { controle acionário }\end{array}$ & EXCONT & $\begin{array}{l}-0,0245 \\
-0,6128\end{array}$ & $\begin{array}{l}0,0880 \\
1,0745\end{array}$ & $\begin{array}{c}-0,048525^{* * *} \\
-2,8625\end{array}$ & $\begin{array}{l}-0,1027 \\
-0,9073\end{array}$ \\
\hline & \multirow{2}{*}{$\begin{array}{l}\text { Oportunidade } \\
\text { de crescimento }\end{array}$} & P_VPA & $\begin{array}{l}0,0107 \\
0,4103\end{array}$ & & & \\
\hline & & CRESREC & & $\begin{array}{l}0,0429 \\
0,4347\end{array}$ & $\begin{array}{l}-0,0061 \\
-0,1153\end{array}$ & $\begin{array}{l}0,0576 \\
0,5869\end{array}$ \\
\hline & Lucratividade & EBITDA_AT & $\begin{array}{l}-0,0098 \\
-0,0921\end{array}$ & $\begin{array}{c}-1,38946 * * * \\
-3,9065\end{array}$ & $\begin{array}{c}-0,465906 * * * \\
-5,4114\end{array}$ & $\begin{array}{c}-1,389122 * * * \\
-3,8530\end{array}$ \\
\hline & Tangibilidade dos ativos & IMOB_AT & $\begin{array}{l}-0,0635 \\
-1,3170\end{array}$ & $\begin{array}{c}-0,40573^{* *} \\
-2,4394\end{array}$ & $\begin{array}{l}-0,0334 \\
-1,4351\end{array}$ & $\begin{array}{c}-0,414768^{* *} \\
-2,4896\end{array}$ \\
\hline & Tamanho & LNAT & $\begin{array}{c}0,142439 * * \\
2,5055\end{array}$ & $\begin{array}{c}0,383561 * * \\
2,5655\end{array}$ & $\begin{array}{c}0,120043^{* * *} \\
3,6080\end{array}$ & $\begin{array}{c}0,388543 * * * \\
2,5952\end{array}$ \\
\hline & Volatilidade & VOLATLO & $\begin{array}{c}0,808905^{*} \\
1,9351\end{array}$ & $\begin{array}{l}0,1497 \\
0,1415\end{array}$ & $\begin{array}{l}-0,1565 \\
-0,6196\end{array}$ & $\begin{array}{l}0,1947 \\
0,1807\end{array}$ \\
\hline & \multirow{2}{*}{ Tipo acionista } & ACFP & $\begin{array}{c}-0,13726 * * \\
-2,2764\end{array}$ & $\begin{array}{l}0,0674 \\
0,5539\end{array}$ & $\begin{array}{c}0,061444 * * \\
2,3416\end{array}$ & $\begin{array}{l}0,0471 \\
0,3921\end{array}$ \\
\hline & & ACPUB & $\begin{array}{l}0,0443 \\
0,6818\end{array}$ & $\begin{array}{l}-0,1942 \\
-1,6263\end{array}$ & $\begin{array}{l}-0,0327 \\
-1,2111\end{array}$ & $\begin{array}{l}-0,1807 \\
-1,5185\end{array}$ \\
\hline & Variação cambial & CAMB & $\begin{array}{c}-0,059142 * * * \\
-2,6133\end{array}$ & $\begin{array}{c}-0,15076 * * * \\
-2,8116\end{array}$ & $\begin{array}{l}0,0457 \\
1,6341\end{array}$ & $\begin{array}{c}-0,155536 * * * \\
-2,8880\end{array}$ \\
\hline & Termo AR & AR1 & & $\begin{array}{c}0,353521 * * * \\
5,5266\end{array}$ & & $\begin{array}{c}0,353843 * * * \\
5,4756\end{array}$ \\
\hline \multicolumn{3}{|c|}{ Número de observações } & 743 & 485 & 614 & 483 \\
\hline \multicolumn{3}{|c|}{ R2 ajustado } & 0,7203 & 0,8367 & 0,8300 & 0,8363 \\
\hline \multicolumn{3}{|c|}{ Estatística Durbin-Watson (DW) } & 1,8643 & 2,0163 & 2,0698 & 1,9949 \\
\hline
\end{tabular}

* significativo a $10 \%$; ** significativo a $5 \%$; *** significativo a $1 \%$ 
seria a primeira opção na hierarquia das fontes de financiamento. Por sua vez, em apenas uma das regressões, uma das proxies utilizadas para oportunidades de crescimento foi significativa a pelo menos $10 \%$, estando positivamente relacionada ao endividamento, reforçando a pecking order.
As evidências relacionadas à aceitação do pecking order no ambiente brasileiro são consistentes com Medeiros e Daher (2008), Gomes e Leal (2000), Procianoy e Schonorrenberger (2004) e Brito e Lima (2005), que também verificaram relação negativa entre lucratividade e endividamento. Por outro lado, as demais variáveis apresen-

Tabela 6 - Regressões para 0 teste IV onde 0 teste DW não detectou autocorrelação

\begin{tabular}{|c|c|c|c|c|c|c|c|}
\hline \multicolumn{2}{|c|}{$\begin{array}{c}\text { VARIÁVEIS } \\
\text { DEPENDENTES }\end{array}$} & PCELPSPL & DIVTSVRMC & PCELPSPL & PCELPSPL & DIVTSVRMC & ELPSPL \\
\hline \multicolumn{2}{|c|}{ Efeitos } & (EA) & (EA) & (EA) & (EF) & (EF) & (EF) \\
\hline \multicolumn{2}{|c|}{ Controle acionário } & CON1 & \multicolumn{3}{|c|}{ CON2 } & \multicolumn{2}{|c|}{ CON3 } \\
\hline \multicolumn{2}{|c|}{ Referência } & (1) & $(2)$ & (3) & (4) & (5) & (6) \\
\hline \multirow{10}{*}{ 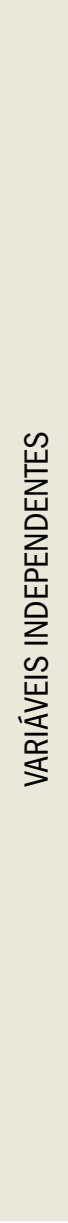 } & EXCONT & $\begin{array}{l}-0,0130 \\
-0,0304\end{array}$ & $\begin{array}{c}-0,2070 * * * \\
-2,7810\end{array}$ & $\begin{array}{l}-0,0130 \\
-0,0304\end{array}$ & $\begin{array}{l}0,0629 \\
0,2578\end{array}$ & $\begin{array}{c}-0,2054 * * * \\
-3,4887\end{array}$ & $\begin{array}{c}-0,2492 * * \\
-2,0417\end{array}$ \\
\hline & P_VPA & $\begin{array}{l}-0,0440 \\
-0,3289\end{array}$ & & $\begin{array}{l}-0,0440 \\
-0,3289\end{array}$ & & & \\
\hline & CRESREC & & $\begin{array}{c}0,0434 * \\
1,9594\end{array}$ & & $\begin{array}{l}0,0133 \\
0,0694\end{array}$ & $\begin{array}{l}0,0234 \\
0,3918\end{array}$ & $\begin{array}{l}0,0312 \\
0,7565\end{array}$ \\
\hline & EBITDA_AT & $\begin{array}{l}-0,3599 \\
-0,9090\end{array}$ & $\begin{array}{c}-0,5110 * * * \\
-3,9105\end{array}$ & $\begin{array}{l}-0,3599 \\
-0,9090\end{array}$ & $\begin{array}{c}-1,2316 * \\
-1,6760\end{array}$ & $\begin{array}{c}-0,5341 * * * \\
-3,2334\end{array}$ & $\begin{array}{c}-0,4640 * * \\
-2,3172\end{array}$ \\
\hline & IMOB_AT & $\begin{array}{c}-0,2974 * * * \\
-6,4563\end{array}$ & $\begin{array}{c}-0,1087^{* *} \\
-2,2415\end{array}$ & $\begin{array}{c}-0,2974 * * * \\
-6,4563\end{array}$ & $\begin{array}{c}-1,0551 * * * \\
-5,8819\end{array}$ & $\begin{array}{c}-0,0745^{* * *} \\
-3,2932\end{array}$ & $\begin{array}{c}-0,1263 * \\
-1,8039\end{array}$ \\
\hline & LNAT & $\begin{array}{c}0,2152 * * * \\
3,0003\end{array}$ & $\begin{array}{l}0,0287 \\
1,1890\end{array}$ & $\begin{array}{c}0,2152^{* * *} \\
3,0003\end{array}$ & $\begin{array}{c}0,6110 * * * \\
4,8110\end{array}$ & $\begin{array}{c}0,1375^{* * *} \\
3,1191\end{array}$ & $\begin{array}{c}0,1602 * * * \\
3,8407\end{array}$ \\
\hline & VOLATLO & $\begin{array}{c}3,5444 * * * \\
3,7943\end{array}$ & $\begin{array}{l}0,2214 \\
0,6380\end{array}$ & $\begin{array}{c}3,5444 * * * \\
3,7943\end{array}$ & $\begin{array}{l}1,0382 \\
0,7141\end{array}$ & $\begin{array}{l}0,0741 \\
0,1938\end{array}$ & $\begin{array}{l}-0,1556 \\
-0,2951\end{array}$ \\
\hline & ACFP & $\begin{array}{l}-0,0627 \\
-0,3221\end{array}$ & $\begin{array}{l}0,0053 \\
0,0488\end{array}$ & $\begin{array}{l}-0,0627 \\
-0,3221\end{array}$ & $\begin{array}{l}-0,0185 \\
-0,1731\end{array}$ & $\begin{array}{c}0,0723 * \\
1,6685\end{array}$ & $\begin{array}{l}0,0008 \\
0,0150\end{array}$ \\
\hline & ACPUB & $\begin{array}{l}-0,0866 \\
-0,6748\end{array}$ & $\begin{array}{l}0,0165 \\
0,3313\end{array}$ & $\begin{array}{r}-0,0866 \\
-0,6748\end{array}$ & $\begin{array}{l}0,0531 \\
0,3132\end{array}$ & $\begin{array}{l}-0,0387 \\
-0,9599\end{array}$ & $\begin{array}{l}0,0719 \\
1,0765\end{array}$ \\
\hline & CAMB & $\begin{array}{c}-0,1504 * * \\
-2,1680\end{array}$ & $\begin{array}{l}-0,0181 \\
-0,7160\end{array}$ & $\begin{array}{c}-0,1504^{* *} \\
-2,1680\end{array}$ & $\begin{array}{c}0,0873 * \\
1,9044\end{array}$ & $\begin{array}{l}0,0362 \\
1,2372\end{array}$ & $\begin{array}{c}-0,0569 * * * \\
-5,9355\end{array}$ \\
\hline \multicolumn{2}{|c|}{ Observações } & 210 & 183 & 210 & 200 & 379 & 428 \\
\hline \multicolumn{2}{|c|}{ R2 ajustado } & 0,1626 & 0,2350 & 0,1626 & 0,8831 & 0,8145 & 0,8111 \\
\hline \multicolumn{2}{|c|}{ Estatística D-W } & 2,0530 & 2,0427 & 2,0530 & 2,1154 & 2,0878 & 1,8961 \\
\hline
\end{tabular}

* significativo a $10 \%$; ** significativo a $5 \%$; *** significativo a $1 \%$ 
tam relações controversas em testes anteriores realizados no Brasil: enquanto Gomes e Leal (2002) verificaram um sinal negativo na relação entre endividamento e oportunidades de crescimento, Brito e Lima (2005) corroboram a relação positiva encontrada no presente estudo. Quanto ao tamanho, Gomes e Leal (2002) verificaram relação negativa com o nível de utilização da dívida, ao contrário de Procianoy e Schonorrenberger (2004), que confirmam a relação encontrada neste trabalho.

Finalmente, a variável tangibilidade dos ativos apresentou-se significativa e positivamente relacionada ao endividamento. Tal relação corrobora a idéia de que as garantias colaterais contribuem para a capacidade de endividamento das empresas. O controle para o período de câmbio fixo apresentou-se significativo, explicitando a importância de se controlar esse tipo de variável macroeconômica.

Cabe ainda levantar algumas limitações deste trabalho e sugestões para estudos futuros: primeiro, os dados fornecidos nas IAN's não são precisos, tendo sido submetidos a diversos tratamentos para este trabalho. Outros pontos que podem ser suscitados são a não consideração de controle exercido por famílias, e de acordos de acionistas. Tais pontos poderiam ser focados em estudos futuros, de forma a aumentar o entendimento da influência das estruturas de propriedade no grau de endividamento das empresas. Um último aspecto importante não focado neste trabalho são os diversos mecanismos de governan- ça corporativa que também podem influenciar a decisão de endividamento.

\section{CONCLUSÕES}

A principal contribuição deste trabalho é a consideração de condições onde há alta propensão à expropriação de minoritários, condições estas presentes em grande escala no Brasil. Adicionalmente, o enfoque por meio de múltiplos métodos aumenta a robustez dos resultados.

Sobre as proposições, cabe resgatar que o estudo apontou que as empresas onde existe um único controlador definido tendem a evitar a dívida, ou possuem dificuldades de se financiar com capital de terceiros. Por sua vez, dentre as empresas com um único controlador definido, aquelas em que o majoritário possui menos direitos a fluxos de caixa são as mais endividadas.

Levando em conta o conjunto das proposições e dos testes efetuados, portanto, considera-se que as evidências suportam a idéia de que a propensão à expropriação, aqui definida como existência de um único controlador em um ambiente de fraca proteção legal aos minoritários e exacerbada pela separação entre direitos a fluxos de caixa e direitos ao voto, influencia o nível de endividamento. Tal conclusão contribui para um maior entendimento acerca da estrutura de capital das empresas negociadas na Bovespa.

Quadro 5 - Resumo dos principais resultados

\begin{tabular}{|c|c|c|c|c|c|}
\hline \multicolumn{6}{|c|}{ TESTES NÃO PARAMÉTRICOS } \\
\hline TESTE & TÉCNICA ESTATÍSTICA & PROPOSIÇAO & VARIÁVEL & SINAL ESPERADO & SINAL ENCONTRADO \\
\hline \multirow{2}{*}{1} & \multirow{2}{*}{ U de Mann-Whitney } & 1 & EXCONT & negativo & negativo(*) \\
\hline & & 2 & EXCONT & positivo & negativo $\left({ }^{*}\right)$ \\
\hline \multirow{2}{*}{ ॥ } & \multirow{2}{*}{ Kruskal-Wallis } & 3 & FCCONT & positivo & ambíguo \\
\hline & & 4 & FCCONT & negativo & ambíguo \\
\hline \multicolumn{6}{|c|}{ TESTES PARAMÉTRICOS } \\
\hline TESTE & TÉCNICA ESTATÍSTICA & PROPOSIÇAO & VARIÁVEL & SINAL ESPERADO & SINAL ENCONTRADO \\
\hline \multirow{2}{*}{ III } & \multirow{2}{*}{ Regressão em painéis } & 1 & EXCONT & negativo & negativo \\
\hline & & 2 & EXCONT & positivo & negativo \\
\hline \multirow{2}{*}{ IV } & \multirow{2}{*}{ Regressão em painéis } & 3 & FCCONT & positivo & negativo \\
\hline & & 4 & FCCONT & negativo & negativo \\
\hline
\end{tabular}

(a): o sinal foi marginalmente positivo em uma das seis relações significantes 


\section{REFERÊNCIAS}

ABRAPP. Associação Brasileira das Entidades Fechadas de Previdência Complementar. Disponível em http://www.abrapp.org.br. Acesso em 21.06.2004.

ADMATI, A; PFLEIDERER, P; ZECHNER, J. Large shareholder activism, risk sharing, and financial market equilibrium. Journal of Political Economy, v. 102, n. 6, p. 1097-1130, 1994.

ALDRIGHI, D; MAZZER NETO, R. evidências sobre as estruturas de propriedade de capital e de voto das empresas de capital aberto no Brasil. RBERevista Brasileira de Economia, v. 61, n. 2, p. 129-152, 2007.

AMIHUD, Y; LEV, B. Risk reduction as a managerial motive for conglomerate mergers. Bell Journal of Economics, v. 12, n. 2, p. 605-617, 1981.

BEBCHUK, L; KRAAKMAN, R; TRIANTIS, G. Stock Pyramids, cross-ownership, and dual class equity: the creation and agency costs of separating control from cash flow rights. WP: SSRN, 1999.

BERLE, A; MEANS, G. A moderna sociedade anônima e a propriedade privada. São Paulo: Abril Cultural, p. 335, 1984.

BRITO, R; LIMA, M. A Escolha da estrutura de capital sob fraca garantia legal: o caso do Brasil. Revista Brasileira de Economia, v. 59, n. 2, p. 177-208, 2005.

CVM - Comissão de Valores Mobiliários. Disponível em http://www.cvm. gov.br. Acesso em 27.08.2003.

DICK, A; ZINGALES, L. Private benefits of control: an international comparison. Journal of Finance, v. 59, n. 2, p. 537-600, 2004.

ECONOMÁTICA. Economática Pró. São Paulo: Economática, 2003.

GOMES, G; LEAL, R. Determinantes da estrutura de capital das empresas brasileiras com ações negociadas em bolsas de valores. In: LEAL, R; COSTA JR, N; LEMGRUBER, E. Finanças corporativas. São Paulo: Atlas, 2000.

GRINSTEIN, Y; MICHAELY, R. Institutional holdings and payout policy. Journal of Finance, v. 60, n. 3, p. 1389-1426, 2005.

GROSSMAN, S; HART, O. Takeover bids, the free rider problem and the theory of corporations. Bell Journal of Economics, v. 11, n. 1, p. 42-64, 1980.

HAIR, J; ANDERSON, R; TATHAN, R; BLACK, W. Multivariate Data Analysis.New Jersey: Prentice Hall, 1998.

HARRIS, M; RAVIV, A. The theory of capital structure. Journal of Finance, v. 45 , n. 2, p. 321-349, 1991.

HSIAO, C. Analysis of Panel Data. Cambridge, MA: Cambridge University Press, 1999.

JENSEN, M. Agency costs of free cash flow, corporate finance and takeovers. American Economic Review, v. 76, n. 2, p. 323-339, 1986.

JENSEN, M; MECKLING, W. Theory of the firm: managerial behavior, agency costs and ownership structure. Journal of Financial Economics, v. 3, n. 4, p. 305-360, 1976.

KENNEDY, P. A Guide to Econometrics. Cambridge, MA: MIT Press, 1998.

LA PORTA, R; LOPEZ-DE-SILANES, F; SHLEIFER, A; VISHNY, R. Corporate ownership around the world. Journal of Finance, v. 54, n. 2, p. 471-518, 1999.
LA PORTA, R; LOPEZ-DE-SILANES, F; SHLEIFER, A; VISHNY, R. Law and finance. Journal of Political Economy, v. 106, n. 4, p. 1113-1155, 1998.

LA PORTA, R; LOPEZ-DE-SILANES, F; SHLEIFER, A; VISHNY, R. Investor protection: origins, consequences, reform. WP: NBER, 1999a.

LEAL, R; CARVALHAL-DA-SILVA, A; VALADARES, S. Estrutura de controle das companhias brasileiras de capital aberto. RAC, v. 6, n. 1, p. $07-18,2002$

LEAL, R; CARVALHAL-DA-SILVA, A; ALOY JR, R; LAPAGESSE, G. Estrutura de controle e valor de mercado das empresas brasileiras. In XXIV Encontro da Anpad-Enanpad, 2000. Florianópolis. Anais... Rio de Janeiro: Associação Nacional de Programas de Pós-Graduação em Administração, 2000, p. 136. Texto integral em CD-ROM

MEDEIROS, O; DAHER, C. Testando teorias alternativas sobre a estrutura de capital nas empresas brasileiras. RAC, v. 12, n. 1, p. 177-199, 2008

MYERS, S. Determinants of corporate borrowing. Journal of Financial Economics, v. 5, n. 2, 147-175, 1977.

MYERS, S. The capital structure puzzle. The Journal of Finance, v. 3, n. 39, p. 575-592, 1984.

MYERS, S; MAJLUF, N. Corporate financing and investment decisions when firms have information that investors do not have. Journal of Financial Economics, v. 13, n. 2, p. 187-221, 1984.

NENOVA, T. Control value and changes in corporate law in Brazil. WP SSRN, 2001.

PEREIRA, S. Análise da relação entre valor e alavancagem no mercado brasileiro. In: Encontro Nacional Associação Nacional de Pós-Graduação e Pesquisa em Administração, 24., 2000. Florianópolis. Anais... Rio de Janeiro: ANPAD, 2000, p. 127. CD-ROM.

PINDICK, R; RUBINFELD, D. Econometric Models and Economic Forecasts. 4. ed. Boston: McGraw Hill, 1998

PROCIANOY, J. Dividendos e tributação: o que aconteceu após 1988-1989. Revista de Administração, v. 31, n. 2, p. 7-18, 1996.

SAITO, R. Share Repurchase rules and expropriation of minority shareholders: evidence from Brazil. In: Encontro Nacional Associação Nacional de Pós-Graduação e Pesquisa em Administração, 25., 2001. Campinas. Anais.. Rio de Janeiro: ANPAD, 2001, p. 171. CD-ROM.

PROCIANOY, J.; SCHONORRENBERGER, A. A influência da estrutura de controle nas decisões de estrutura de capital das companhias brasileiras. Revista Brasileira de Economia, v. 58, n. 1, p. 121-146, 2004.

TERRA, P. An empirical investigation on the determinants of capital structure in Latin America. In: Encontro Nacional Associação Nacional de PósGraduação e Pesquisa em Administração, 26., Salvador. Anais... Rio de Janeiro: ANPAD, 2002, p. 231. CD-ROM.

TERRA, P. Three essays on international business. Ph. D. Dissertation, McGill University, Montréal, Canada, 2002b.

TITMAN, S; WESSELS, R. The determinants of capital structure choice. Journal of Finance, v. 43, n. 1, p. 1-19, 1988.

VALADARES, S. Estrutura de controle e propriedade de empresas brasileiras. In Bonono, M. Finanças aplicadas ao Brasil. Rio de Janeiro: FGV, 2002. p. 275-298.

VALADARES, S.; LEAL, R. Ownership and control structure of Brazilian companies. Abante, v. 3, n. 1, p. 29-56, 2000. 